\title{
Sustainable care improvement programs supported by undergraduate health care education
}

\author{
Carolien H. M. Smits ${ }^{* 1}$, Annelies Harps-Timmerman ${ }^{1}$, Jan S. Jukema ${ }^{2}$, Annemiek Stoopendaal ${ }^{3}$, Ad M. Kamper ${ }^{4}$, \\ Mathilde M.H. Strating ${ }^{3}$, Roland Bal ${ }^{3}$ \\ ${ }^{1}$ Windesheim University of Applied Sciences, Zwolle, Netherlands \\ ${ }^{2}$ Saxion University of Applied Sciences, Deventer, Netherlands \\ ${ }^{3}$ Erasmus University Rotterdam, Department of Health Policy and Management, Rotterdam, Netherlands \\ ${ }^{4}$ Isala Clinics, Zwolle, Netherlands
}

Received: February 22, 2017

DOI: $10.5430 /$ cns.v5n3p26
Accepted: May 17, 2017

Online Published: June 8, 2017

\begin{abstract}
Background: The Care for Better Region program was developed to achieve sustainable care improvement focusing on fall prevention. Key ingredients involved improvement teams developing and implementing a falls reduction plan, Practice Development; facilitation of improvement teams by lecturers and undergraduate health care students; an implementation phase. This study evaluates the impact of this program on: (1) the number of falls incidents, and (2) the sustainability of care improvement practice.

Methods: A realist evaluation design was used. Nine improvement teams participated in the Care for Better Region program. Staff members registered falls incidents in two measurement cycles in the participating teams $(\mathrm{N}=143$ older adults $)$ and in a control group $(\mathrm{N}=93)$. Data collection on improvement sustainability involved participative observations, interviews, logs of students and lecturer coaches, minutes and evaluations.

Results: The falls incidents on the participating wards decreased over 12 months from $13.3 \%$ to $1.4 \%$. At the control wards they stabilized. Sustainability of improvement practice: (1) Involvement of improvement teams was enhanced by measurements of falls incidents. However, involvement of ward staff was difficult to accomplish; (2) Students, lecturer coaches and project leaders of the improvement teams learned how to involve stakeholders, implement project management, and how to prevent falls incidents; (3) Network facilitation was promoted by the central meetings. The project leaders' meetings continued after the project; (4) Students facilitated the improvement teams. The change of students after six and twelve months inspired the teams to renew their focus.

Conclusions: This exploratory realist evaluation study shows how the Care for Better Region program improved sustainability of falls incidents reduction. The program also had a positive impact on the sustainability of improvement practice. Nursing education should focus on the development of innovation and facilitation skills in students. Nursing practice may improve by interdisciplinary collaboration with undergraduate health care education in care improvement programs.
\end{abstract}

Key Words: Care improvement, Collaboration care organization and professional education, Falls prevention, Practice Development, Sustainability

*Correspondence: Carolien H. M. Smits; Email: CHM.Smits@ windesheim.nl; Address: Windesheim University of Applied Sciences, Postal Box 10090, 8000 GB, Zwolle, Netherlands. 


\section{INTRODUCTION}

Over the last decades, care improvement programs have become a regular part of organizational processes in health care. Breakthrough Models have been used in projects worldwide. ${ }^{[1-3]}$ In 2005 the Dutch government initiated the Care for Better program. Improvement teams of different healthcare organizations collaborated in this interdisciplinary program to improve the quality of care on a single improvement theme. The program enabled the creation of a national network, so all improvement teams could learn from each other. This program has been implemented in more than 580 organizations and over a 1,000 teams, tackling 25 improvement themes, including falls prevention and client involvement. $^{[2,4]}$ Many improvement teams are led by nurses. Nurses' leadership in care improvement practices has turned out to be challenging. ${ }^{[5]}$ For this reason improvement teams are coached by care innovation experts. The Care for Better program has been shown to be a fairly effective form of spreading new knowledge into practice and improving the quality of health care. ${ }^{[2]}$ However, concerns have been raised on the sustainability of the improvements, as improvements have been known to dwindle after the completion of improvement programs. ${ }^{[4,6]}$

For this reason a new care improvement program, Care for Better Region was developed, based on the national Care for Better program aiming to achieve sustainable care improve-

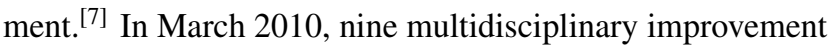
teams joined the new improvement program in a pilot study.
The teams worked in a variety of wards providing nursing home care, homecare and hospital care. The focus of the improvement theme was fall prevention in older adults. Care for Better Region was evaluated using a combination of qualitative and quantitative methods. In this article we describe the results of this evaluation. The research questions are: (1) What is the impact of the Care for Better Region program on the number of falls incidents? (2) What is the impact of the Care for Better Region program on the sustainability of improvement practice in falls prevention?

\subsection{Care for Better Region program}

The Care for Better Region program was developed by a consortium consisting of a university of applied sciences (nursing education and Reseach group on Innovation of Care of Older Adults), regional care organisations, regional and national organizations in the field of professional nursing education, care for older adults, and a national center of expertise on falls prevention. Care for Better Region aims to facilitate sustainable results by adding new ingredients to the regular recipe of Dutch care improvement programs.

\subsubsection{Ingredients of regular care for better program}

The ingredients of the regular Care for Better Programs include: (1) multidisciplinary care improvement teams, (2) Plan-Do-Study-Act cycles, (3) regular team meetings and training sessions, (4) consultation of experts on content of innovation (e.g., falls prevention) and improvement strategies $^{[2]}$ (see Figure 1).

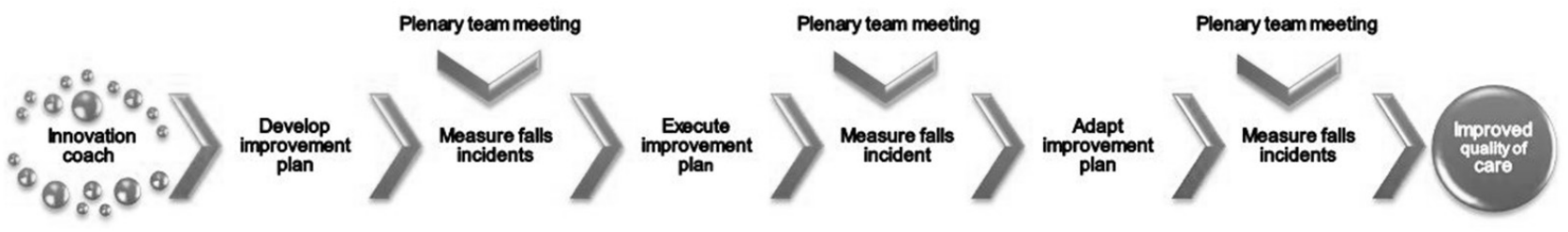

Figure 1. Care for Better program

\subsubsection{Multidisciplinary care improvement teams}

A team is expected to include at least a project manager, a general manager, an official in charge of quality improvement, a client or client representative, and a care staff member. Other professionals may also join the team. The project manager has a key role in this team and is selected by the healthcare organization on the basis of criteria concerning higher education (bachelor degree), experience and organizational leadership.

\subsubsection{Plan-Do-Study-Act cycles}

The improvement team starts by analyzing the strengths and weaknesses of their care organization and ward with respect to the topic of improvement. Strengths and weaknesses may be sought at different levels in the organization: managerial, staff, individual, working processes or group culture. Next, the team focuses on their care improvement plan, describing the aims, processes, interventions, investments and planning. The improvement plans are implemented according to a Plan-Do-Study-Act strategy. ${ }^{[8]}$ Plans are made with specific, measurable targets, e.g., a falls reduction of $40 \%$. The care improvement plan describes the intervention (Do) and the indicators used to measure progress (Study). In the case of falls prevention the measure usually chosen is number of (near) falls at a ward, measured during a fixed period. Three measurement cycles are executed: at the start, after six months and at the end of the trajectory. The results of every 
cycle is discussed by the team members and the improvement plan may subsequently be adapted to the results (Act).

\subsubsection{Team meetings and training sessions}

In Care for Better programs, care improvement teams meet during three one-day meetings at a national level. During these meetings they are presented with new information (e.g. on falls prevention, care improvement development and implementation). The teams exchange their care improvement plans, progress, products and results to each other by means of presentations, and informal information exchange markets. During the meetings they also work in teams on their care improvement plans. The meetings are meant to inspire the teams to continue their work. All teams may exchange products and know-how on a dedicated website.

\subsubsection{Expertise on content of innovation and improvement strategies}

A team of external experts on the topic of interest is added to the care improvement trajectory. Their competencies expand to processes and strategies of care improvement.

\subsection{Ingredients added to the Care for Better Region pro- gram}

To create sustainable changes, new ingredients were added to the recipe of the regular improvement program. The new ingredients consist of (1) involvement of health care students as members of care improvement teams, (2) application of the innovation strategy of Practice Development, (3) the support from lecturer coaches, (4) team meetings and exchanging expertise and products at a regional instead of a national scale, and (5) an implementation phase.

\subsubsection{Students as members of care improvement teams}

Undergraduate health care students (nursing, occupational therapist, speech therapy) constitute new team members that support the improvement team. They are third year students completing different minor courses. Their main responsibilities are doing desk research, elaborating the care improvement plan, facilitating data collection, elaborating on the improvement and dissemination plans and related odd jobs. To students the Care for Better Region acts as a powerful learning environment that allows them to develop their facilitation competencies. ${ }^{[9]}$ Two students are added to every improvement team. Every 6 months a new student couple is added to the teams, as students should complete their education targets in six months. Every team is thus facilitated by three different student couples. This facilitation is expected to make it easier for teams to achieve their improvement aims and to make their achievements more sustainable.

\subsubsection{Practice Development}

In Care for Better Region the improvement teams use Practice Development as an approach to reach sustained care improvements. Practice Development is a continuous process of improvement towards increased effectiveness in patient centered care. It is a comprehensive and systematic way to learn from and improve practice at the same time. ${ }^{[10]}$ It acknowledges and focuses on the local context of practice improvement while paying attention to all organisational levels. It supports a practice improvement in which there is systematic attention to and development of evidence, context and facilitation. Within this strategy attention is paid to the empowerment of all stakeholders involved, especially members of the improvement teams, change of cultures, and use of different kinds of knowledge (professional, experiential, scientific). Its focus on learning and change of culture makes Practice Development an appropriate approach to make Care for Better Region results last. It involves the exploration of beliefs and values of all stakeholders, sharing good ideas and seeing which fits best and empowerment of staff through skilled facilitation, networks of support and by sharing the vision with all stakeholders. ${ }^{[11]}$ Studies have shown Practice Development to support effective improvements. ${ }^{[12]}$

\subsubsection{Support from lecturer coaches}

Lecturer coaches support the teams by giving feedback on the care improvement plans and the chosen strategies. They are not selected on the basis of their expertise in the topic of improvement, although they should feel committed to it, but on the basis of their expertise in communication and coaching skills. The two lecturer coaches are trained to be Practice Development facilitators. They facilitate the project managers and improvement teams in all processes necessary to accomplish their goals. By facilitating a culture change, the efforts of lecturer coaches are expected to lead to sustainable improvements.

\subsubsection{Regional team meetings and exchanging expertise and products}

The overall project organization facilitates three central meetings for the improvement teams and various training sessions for the project managers. The teams receive and exchange information as in the regular program meetings. In line with an important Practice Development principle, however, the main focus is on the empowerment of teams. As distances between improvement teams are smaller in a regional context than in a national context, this may lead to more sustainable improvements, as teams and project managers can meet more easily. 


\subsubsection{Implementation phase as an extended care improve- ment trajectory}

The new trajectory differs from the usual trajectory in that more time (18 months instead of the regular 12 months) is taken in the initial stages to make sure that care improvements are the result of the improvement teams' efforts, rather than those of the coaches and experts. The extra six months are added to elaborate on the sustenance of the results.

\section{Methods}

\subsection{Design}

This study uses a realist evaluation design. In realist review the views and practices of practitioners in defining and dealing with complexity in specific programs are acknowledged. ${ }^{[13-15]}$ Data collection involved both quantitative and qualitative data focusing on nine improvement teams that implemented the Care for Better program and nine control wards. Moreover, the evaluation followed a formative, actionoriented approach in that intermediate results were used to improve on interventions, thus in line with the improvement program itself. ${ }^{[16-18]}$

\subsection{Setting and participants}

From September 2009 till October 2011 nine improvement teams in six care organizations implemented the Care for Better Region program, to improve their activities aimed to decrease the number of falls incidents on the wards. Five improvement teams were located on wards with older persons with dementia, four improvement teams were located on wards with older persons with physical disabilities. Each improvement team consisted of one or two nurses or nurseassistants, the manager of the ward, a physiotherapist, two bachelor health care students and a project leader. During Care for Better Region undergraduate students and researchers (AHT, AS, MS) collected data. The data gathered for this realist evaluation study, were also used in a formative way to provide the improvement teams with feedback on the progress of their care improvement plans. ${ }^{[15]}$ Data were collected on the nine participating wards and (for the quanti- tative data on falls incidence) on five similar control wards. These control wards were located in two nursing homes that also included participating wards.

\subsection{Data collection and analyses}

Qualitative and quantitative methods were used in answering the research questions. Table 1 provides an overview of the data collection methods. All data were anonymized before analysis.

\subsubsection{Falls incidents}

To answer the research question on the impact of Care for Better Region on falls incidents we used quantitative methods. Measurement strategies were comparable to earlier Care for Better studies. ${ }^{[2,4,6]}$ The quantitative data consisted of measurements of the fall incidents of the older adults $(\mathrm{N}=143)$ of the participating wards and the measurements of a control group of similar older adults $(\mathrm{N}=93)$. Over a period of three weeks in April 2010 (T0) and April 2011 (T1) all fall incidents of the participating wards and the control wards were registered. This registration was done by staff members describing the incidents on sticky memo's and attaching them to a poster that was hung in the ward. The contents of the memos were transposed to a spreadsheet. Each memo described the time of the falls incident, its cause and any impact for the physical health of the older adults. The analyses of quantitative data on fall incidents focused on the mean changes between falls measurements using crosstabs, paired-samples $t$-tests and independent samples $t$-tests.

\subsubsection{Sustainability}

In line with Practice Development principles, sustainability was defined as an attributable impact from the Care for Better Region program that continues to be present over time (months and years) associated with the continued presence of process outcomes which are encompassed by the attributes of an effective workplace culture. ${ }^{[20]}$ These process outcomes involve: the involvement of stakeholders, learning and knowledge, network facilitation and facilitation by students and lecturer coaches.

Table 1. Data collection

\begin{tabular}{|c|c|}
\hline \multicolumn{2}{|l|}{9 Participating teams: } \\
\hline Staff measurements & 3 times 3 week period: falls incidents \\
\hline $\begin{array}{l}\text { Observations students and } \\
\text { researcher }\end{array}$ & $\begin{array}{l}\text { Continuous: ward observations, student training sessions, improvement team meetings, general team } \\
\text { meetings, steering group meetings, sounding board meetings, team leaders evaluation meeting }\end{array}$ \\
\hline Interviews by researcher & $\begin{array}{l}\text { Individual interviews: } 8 \text { team members, } 6 \text { team leaders, } 2 \text { lecturer coaches } \\
\text { Group interview: students }\end{array}$ \\
\hline \multicolumn{2}{|l|}{9 Control wards: } \\
\hline Staff measurements & 3 times 3 week period: falls incidents \\
\hline
\end{tabular}


To answer the question if Care for Better Region led to sustainable improvement of fall prevention participative observations, interviews and logbook data were collected. The structured observations were carried out by the students and one of the researchers (AS). Prior to data collection, the undergraduate students were trained in observation data collection and followed an introduction to Practice Development. Researcher AS interviewed eight team members, six team leaders and two lecturer coaches. A group of eight students was interviewed in an evaluation session. Interviews were audio taped and transcribed verbatim. The students and researcher observed and recorded in observation notes the student training sessions, the improvement team meetings, the three general meetings with all improvement teams, the steering group meetings and the sounding board meetings and the two project evaluation meetings with the team leaders. Students also observed the residents of the wards and the environment of the residents of the ward from the perspective of falls indicators. Observation notes were taken free-hand at the moment and transcribed immediately after the observation. Observations to indicate sustainability of the improvement of fall preventions were obtained from Practice Development principles, focusing on the involvement of stakeholders, learning and knowledge, network facilitation and facilitation of students and lecturers. Logs of students and lectures coaches and records of meetings, presentations, evaluations were used to complete the data triangulation.
The qualitative data were analyzed using thematic content analysis based on the above mentioned process outcomes derived from Practice Development: ${ }^{[20]}$ (1) the sustainability of the involvement of stakeholders, (2) learning and knowledge, (3) network facilitation and (4) facilitation by students and lecturer coaches.

\section{RESUlTS}

\subsection{The impact of Care for Better Region on falls inci- dents of older adults}

The number of falls incidents in the participating wards had decreased after twelve months with $11.9 \%$ (see Table 2). The first measurement cycle (T0) shows a significant difference between the participating wards and the control wards. The number of fall incidents on the participating wards is higher than on the control wards $(t=2.70 ; p=.10)$. The second measurement cycle (T1) shows less difference between the participating wards and the control wards. The control wards stabilized and the participating wards decreased significantly, resulting in higher scores for the control wards. Looking at the number of residents with multiple falls, similar results are seen. The difference between the participating and control wards is marginally significant when looking at the number of residents with multiple falls at baseline $(t=-1.80 ; p=.08)$. At $\mathrm{T} 1$ the difference is no longer significant $(t=0.51 ; p=.61)$.

Table 2. Changes in falls incidents at the participating and control wards

\begin{tabular}{llllll}
\hline \multirow{2}{*}{ Number of residents at the ward } & \multicolumn{2}{c}{ Participating $(\mathbf{N}=\mathbf{1 4 3}), \mathbf{N}(\%)$} & & \multicolumn{2}{c}{ Control (N = 93), N (\%) } \\
\cline { 2 - 3 } \cline { 5 - 6 } & T0 & T1 & T0 & T1 \\
\hline Number of falls incidents (\% falls incidents) & $19(13.3 \%)$ & $2(1.4 \%)$ & & $6(6.5 \%)$ & $5(5.4 \%)$ \\
Number of clients falling more than once & $6(4.2 \%)$ & $2(1.4 \%)$ & & $1(1.1 \%)$ & $1(1.1 \%)$ \\
\hline
\end{tabular}

3.2 The impact of Care for Better Region on the sustainability of the improvements on falls prevention

\subsubsection{The involvement of stakeholders}

Care for Better Region started with a central meeting of all improvement teams. During this meeting some improvement teams indicated that they did not want to focus on falls prevention, because they did not experience any problem in this area. The improvement theme (falls prevention) had been chosen by their organizational managers. After the first cycle of falls incidents registration had shown a significant amount of falls, however, all teams saw and supported the need to focus on falls prevention. The data revealed the value and therefore the necessity of care improvement.

Practice Development techniques such as Claims, Concerns, Issues allowed all improvement team members to have a say in the team discussions. "It makes them involved. They are made involved by it. And it is not a project leader that is now telling them what they should do, but it is their own thing. That's what I see.. Really the idea that with this everybody's own involvement is appealed to, on their own ... enthusiasm." (lecturer coach A). Involvement of staff of the participating wards proved to be more difficult to achieve than the involvement of the members of the improvement teams. Students facilitated staff members in implementing the measurements and the interventions to decrease fall incidents. This was appreciated, as staff members experienced time pressure. It also meant, however, that staff members experienced limited pressure to be involved in improvement activities. Lecturer coaches therefore invested more time to demonstrate the importance of ownership to the teams. 


\subsubsection{Learning and knowledge}

Students, lecturer coaches and leaders of the improvement teams were trained in facilitation skills according to Practice Development principles. They learned how to involve all stakeholders, to implement effective project management, to state questions about falls prevention so they can find the information that fits in their specific context. Some project leaders indicated that they missed ready to use information on falls prevention intervention measures. They did not actively search for information themselves, as suggested by the Practice Development approach, but were inclined to wait for relevant information. This may have to do with the fact that the evidence based information was difficult to understand for the care professionals. "I have here, what's it called .. that doctors, that guideline. Well you really have to study it to derive from it what could be handy for you... So that translation from evidence based material to practice. That is difficult for them" (interview lecturer coach B). This translation was eventually offered in a presentation on evidence based falls prevention interventions by a falls prevention expert. After this presentation the Plan Do Study Act strategy was truly implemented in the teams.

\subsubsection{Network facilitation}

Three central meetings with all members of all improvement teams were organized at six months intervals. Not all members attended these meetings, but all teams were represented. The meetings focused on the exchange of ideas, products, and interventions to decrease the falls incidents on the wards. For example; one improvement team developed a pocket size card with the Risks of Falling of Older Adults on one side and on the other side the Interventions to Prevent Falls incidents. The other improvement teams were very enthusiastic about this product and copied it. The pressure to show results every six months helped stakeholders to stay focused on the improvement program. Attendance of the central meetings and thus network building was facilitated by the presentations of experts on falls prevention or on Practice Development principles. Project leaders appreciated the opportunities to link with other project leaders: "And I thought it fantastic that they called for further contact, you know. That some project leader just states: 'Hey, it takes too long before we meet again... We have to plan something before summer.' I liked hearing that." (lecturer coach A). Network building resulted in long-lasting networks, illustrated by the fact that the project managers kept up their meetings for three years after the project was completed.

\subsubsection{Facilitation by students and lecturer coaches}

Students and lecturer coaches were important stakeholders during the improvement program. Students facilitated the improvement teams on a daily basis by making a project plan,

Published by Sciedu Press communicating with the staff members of the wards, doing observations and giving feedback. At the start of the project some students were unsure of their role. They asked: "What am I supposed to do in the care organization?", and "How can I meet the requirements of my education?" Therefore, the lecturer coaches started each new group of students off with a lesson on the project, the students' role and the task they could proceed within the institutions. Communication with students focused on balancing the things students had to do for their personal educational goals and those they had to do for the improvement program. Students felt that their facilitating role was of significance. "Everything I did was for real, the members of the improvement team listened to what I said." Some students claimed that they were the actual owners of the project and not merely the facilitators. One student said, "I felt as if I were the owner of the whole project." This was a potential risk, because for sustainability it is important that the members of the improvement teams and the staff members experienced ownership of the project. The lecturer coaches discussed this risk with the students and the improvement team to stress the importance of shared involvement.

All students participated during six months. Each couple was thus replaced by a new couple. The routines of the nursing university and the care organizations did not always run parallel. This required timely communications and planning. At the same time every change of students offered an opportunity for the improvement team to focus again on the improvement program, because the new students asked after the status of the improvement program, implemented a new measurement cycle and put in fresh energy. To some teams the students were the embodiment of falls prevention or of the improvement program. "The sticky memo measurements really created awareness. But the fact that I was walking around the ward focused the attention, I was myself some sort of implementation." (student).

\section{Discussion}

This study focused on the implementation of a new regional care improvement program aiming to improve care in a sustainable manner. The number of falls incidents on the participating wards decreased over 12 months from $13.3 \%$ to $1.4 \%$ whereas it stabilized over time in the control wards (research question 1). The impact of Care for Better Region on fall incidents after 12 months is comparable to the impact of the national Care for Better improvement program, measured after 12 months. ${ }^{[2,6,21]}$

The impact of the new Care for Better Region program on the sustainability of improvement practice focused on four Practice Development process outcomes: involvement of 
stakeholders, learning and knowledge, network facilitation and facilitation by students and lecturer coaches (research question 2). The resulting themes show that the impact of the new program on the sustainability is most clear in the process outcome of network facilitation and facilitation by students. The improvement teams and project managers appreciated the interaction with other teams and teams members and used each other's products. They continued meeting long after the completion of the project. The facilitation by students was effective as every six months a new couple of students made a fresh start urging the improvement team and project manager to continue their efforts. The students and lecturer coaches also facilitated the involvement of the team members and other stakeholders and learning processes. In some teams this support promoted ownership in students, whereas team members, due to time pressure, may have felt inclined to "lean back". Extra encouragement from lecturer coaches was effective to counterbalance this.

Although this study does not allow for any conclusions on the differential impact of the new ingredients of the Care for Better Region Program, the regional collaboration between professional education and care organizations and the Practice Development strategy seem to have an impact, in particular on the sustainability of the care improvements. The immediate impact of Breakthrough and other care improvement programs has been demonstrated before ${ }^{[2]}$ and matches the results of interventions to reduce falls in nursing care facilities or hospitals. ${ }^{[19]}$ The current study suggests that regional collaboration between professional education and care organizations is effective in achieving sustainable changes. Furthermore, the needs of health care students and professionals to learn can be matched in a regional professional environment and thus contribute to care improvement. ${ }^{[7,9,22]}$

A number of principles and methods from Practice Development focus on sustainable practice changes. The students' systematic facilitation of and continuous contributions to the improvement teams encouraged the teams to continue their improvement efforts. From an educational point of view the deliberate facilitation by students of learning in team and staff members is valuable. The students practiced their facilitation competencies. ${ }^{[9]}$ The members of the improvement teams also learned how to develop and implement improvement plans, to use evidence based knowledge and to learn from each other. Students and team members thus contributed to a culture change on the ward. ${ }^{[9,20]}$

The methodology for the qualitative study involved data collection using participative observations, interviews and logbook data in stakeholders such as students, team leaders, team members, staff members, lecturer coaches and board members. Data collection and analysis was combined with practice innovation, and, in a loose manner, Practice Development principles. This study shows the usability of this approach. Practice Development has been criticized for its lack of systematic evaluation. ${ }^{[20]}$ The use of a diversity of data collection approaches and the need to consider the interests and expectations of the full range of stakeholders, as used in the current study, is suggested to be crucial elements in a more systematic evaluation of Practice Development. ${ }^{[20]}$

The complexity of healthcare interventions and evaluations has thus far received insufficient attention. Choosing a specific evaluation always results in some complexities being highlighted, whereas others remain in the shade. ${ }^{[15]}$ Our realist evaluation design acknowledges professional and educational complexities. The complexities associated with the clients' perspectives may have remained in the shade, as clients were not directly included in the evaluation. The strengths of the current study lie in its rich qualitative data and the pragmatic approach of the realist evaluation design. Data triangulation concerned data collection, in particular type of data and collector. The realist evaluation allows for conclusions on the impact of the new care improvement program on the number of falls incidents and a comparison with national data on care improvement programs. Validity may be good, but the small number of incidents and the fact that any unplanned changes in the wards and their residents were not controlled for calls for careful conclusions.

The project findings led to sustainable care improvements. Moreover, the sustainability of the new care improvement program is now reflected in the nursing curriculum. As of 2014, the principles of the new program are implemented in the Windesheim undergraduate nursing minor Care Innovation. Furthermore, various research projects have been conducted using the ingredients of the Care for Better Region Program and involving the students of the minor Care Innovation.

\section{Conclusions}

The regional collaboration between professional health care education and care organizations make care improvement programs more sustainable, while maintaining similar impact on the care improvement itself. The Care for Better Region program contributes to innovation in nursing education and health care practice.

The current findings lead to some implications for professional education and practice. Nursing education should focus on the development of innovation and facilitation skills in students. Linking courses to care improvement programs offers students an authentic learning environment to practice 
these skills. Similarly, nursing practice may benefit from collaborating with nursing education in care improvement programs. Future research may address the impact of care improvement programs in a larger number of participating teams, in order to allow for sufficient power. Research and care practice may also focus on the impact of improvement programs focusing on other themes such as correct medication processes or the empowerment of residents.

\section{ACKNOWLEDGEMENTS}

This study was financed by the Netherlands organization for Health Research and Development and Windesheim University of Applied Sciences, Zwolle, the Netherlands.

\section{CONFlicts of InTEREST Disclosure}

The authors declare they have no conflict of interest.

\section{REFERENCES}

[1] Øvretveit J, Bate P, Cleary P, et al. Quality collaboratives: lessons from research Qual. Saf. Health Care. 2002; 11: 345e351.

[2] Strating M, Nieboer A, Zuiderent-Jerak T, et al. Creating effective quality improvement collaboratives: a multiple case study. BMJ Quality and Safety. 2011a; 20(4): 344-350. PMid: 21270070. https ://doi.org/10.1136/bmjqs.2010.047159

[3] Slaghuis SS, Strating M, Bal R, et al. A framework and a measurement instrument for sustainability of work practices in long-term care. BMC Health Services Research. 2011; 11: 314. PMid: 22087884. https://doi.org/10.1186/1472-6963-11-314

[4] Strating MMH, Stoopendaal AMV, Zuiderent-Jerak T, et al. Op weg naar duurzaam verbeteren in de langdurige zorg? Tussenresultaten van het nationaal verbeterprogramma Zorg voor Beter (On the way to sustainable improvement in long-term care? Intermediate results of the national improvement program Care for Better). TSG. 2009; 87(8): 374-383. https://doi.org/10.1007/BF03082304

[5] Span M, Smits C. Leadership manifestations in care for older adults: a qualitative study in a care innovation program. NERP Nurs. Educ. Res. Pract. 2013; 4: 138-146.

[6] Strating MMH, Stoopendaal A, Slaghuis S, et al. De weg naar duur zame kwaliteit in de langdurende zorg (The road to sustainable quality in long-term care)? In: Minkman M, Balsters H, Mast J en Kuiper M (red). Blijvend zorgen voor Beter (Maintaing Care for Better). Succesvol verbeteren in de langdurende zorg (Successful improvement in long term care). Vilans/Kluwer, Utrecht. 2011b. Chapter 6.

[7] Stoopendaal A, Strating M, Harps A, et al. Regionale Samenwerking tussen onderwijs en zorginstellingen in het project Zorg voor Beter Regionaal (Regional cooperation between educational and care institutions in the Regional Care for Better Project). Verpleegkunde. (Nursing). 2014; 2: 18-23.

[8] Deming WE. The New Economics for Industry, Government, and Education. Cambridge, MA: The MIT Press; 2000. 265 p.

[9] Jukema JS, Harps-Timmerman A, Stoopendaal A, et al. A care improvement program acting as a powerful learning environment to support nursing students learning facilitation competencies. Nursing Education in Practice. 2015; 15(6): 457-462. https://doi.org/ 10.1016/j.nepr. 2015.04.006

[10] Rycroft-Malone J. Research implementation, evidence, context and facilitation - the PARISH framework. In: McCormack, B., Manley, K., Garbett, R., (Eds.), Practice development in Nursing. Blackwell Publishing, Oxford; 2004. https://doi.org/10.1002/978047 0698884.ch6

[11] Garbett R, McCormack B. A concept analysis of practice development. NT Research. 2002; 7: 87-99. https://doi.org/10.1177/ 136140960200700203
[12] McCormack B, Dewing J, Breslin L, et al. Practice development: realizing active learning for sustainable change. Contemporary Nurse. 2009; 32: 92-104. PMid: 19697981. https://doi.org/10.5172/ conu. 32.1-2.92

[13] Greenhalgh T, Kristjansson E, Robinson V. Realist review to understand the efficacy of school feeding programmes. British Medical Journal. 2007; 335(7625): 858. PMid: 17954518. https: //doi.org/10.1136/bmj .39359.525174.AD

[14] Greenhalgh T, Humphrey C, Hughes J, et al. How do you modernize a health service? A realist evaluation of whole-scale transformation in London. Milbank Quarterly. 2009; 87(2): 391-416. https://doi.org/10.1111/j.1468-0009.2009.00562.x

[15] Broer T, Bal R, Pickersgill M. Problematisations of Complexity: On the Notion and Production of Diverse Complexities in Healthcare Interventions and Evaluations. Science as Culture. 2017; 26(2): 135 160. PMid: 28515573. https://doi.org/10.1080/09505431.2 016.1212003

[16] Bate P, Robert G. Studying health care 'quality' qualitatively: the dilemmas and tensions between different forms of evaluation research within the UK National Health Service. Qualitative Health Research. 2012; 12(7): 966-981. PMid: 12214681. https://doi.org/10.1 $177 / 104973202129120386$

[17] Øvretveit J. Action evaluation of health programmes and change. A handbook for a user focused approach. Oxford: Radcliffe Medical Press; 2002.

[18] Bal R, Mastboom F. Engaging with technologies in practice: travelling the North-west passage. Science as Culture. 2007; 16 (3): 253-266. https://doi.org/10.1080/09505430701568651

[19] Cameron ID, Murray GR, Gillespie LD, et al. Interventions for preventing falls in older people in nursing care facilities and hospitals. Cochrane Database of Systematic Reviews. 2010; 12(1): CD005465. https://doi.org/10.1002/14651858.cd005465.pub2

[20] Manley K, Sanders KM, Cardiff S, et al. Effective workplace culture: the attributes, enabling factors and consequences of a new concept. International Practice Development Journal. 2011. Available from: http://www.fons.org/Resources/Documents/J ournal/Vol1No2/IPDJ_0102_01.pdf

[21] Broer T, Nieboer AP, Bal RA. Opening the black box of quality improvement collaboratives: An actor-network theory approach. BMC Health Services Research. 2010; 10: 265. PMid: 20825648. https://doi.org/10.1186/1472-6963-10-265

[22] Stoopendaal A, Strating M, Harps A, et al. 'Met andere ogen'. Zorgverbetering en borging in het project Zorg voor Beter Regionaal ('From another viewpoint'. Care improvement and assurance in the Regional Care for Better Project). Kwaliteit in Zorg (Qual. Care). 2013; 4: 25-29. 